\title{
The complex advanced endoscopic approach in the treatment of choledocholitiasis and empyema of gallbladder
}

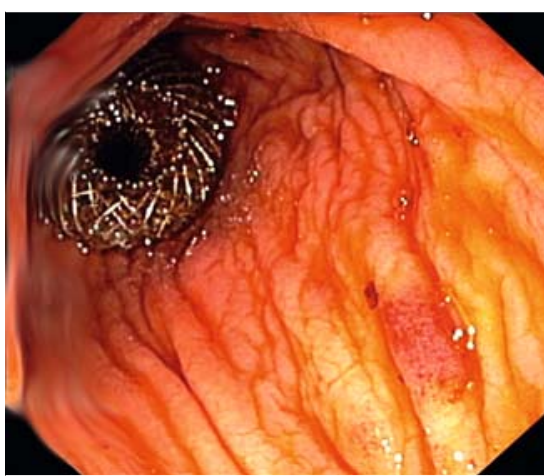

- Fig. 1 Cholecystogastrostomy under endoscopic ultrasound guidance using a Hot Axios stent $(10 \times 10 \mathrm{~mm})$.

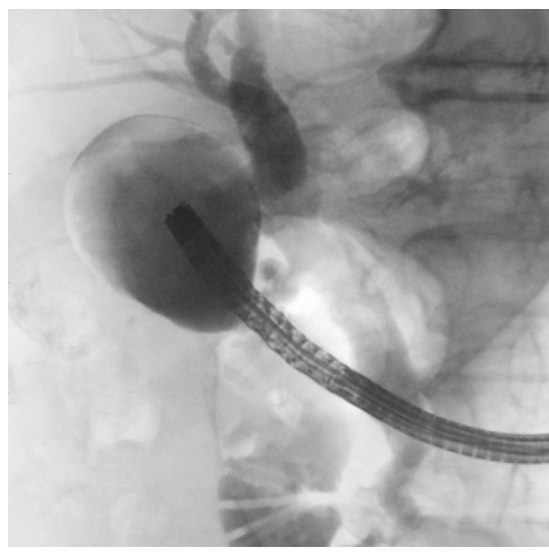

- Fig. 4 Gallbladder after removal of stones confirmed on fluoroscopy.

Advanced endoscopic procedures using a cholangioscope and performed under the endoscopic ultrasound (EUS) guidance for minimally invasive therapy of complex biliary diseases has become a promising treatment modality in selected cases [1-3].

An 88-year-old man was admitted to the surgical department with clinical signs of cholangitis. Imaging revealed a gallbladder empyema with dilation of the common bile duct (CBD) up to $25 \mathrm{~mm}$.

During endoscopic retrograde cholangiopancreatography (ERCP), biliary stones in the CBD up to $20 \times 30 \mathrm{~mm}$ were seen. Sphincterotomy allowed drainage

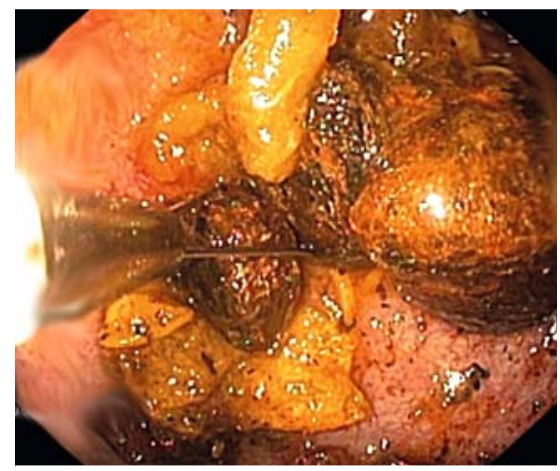

- Fig. 2 Cholecystoscopy through the lumen of the lumen-apposing metal stent.

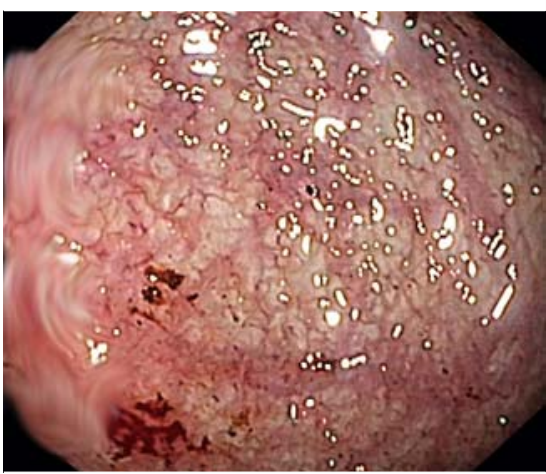

- Fig. 3 Revision of the gallbladder with SpyScope after electrohydraulic lithotripsy.

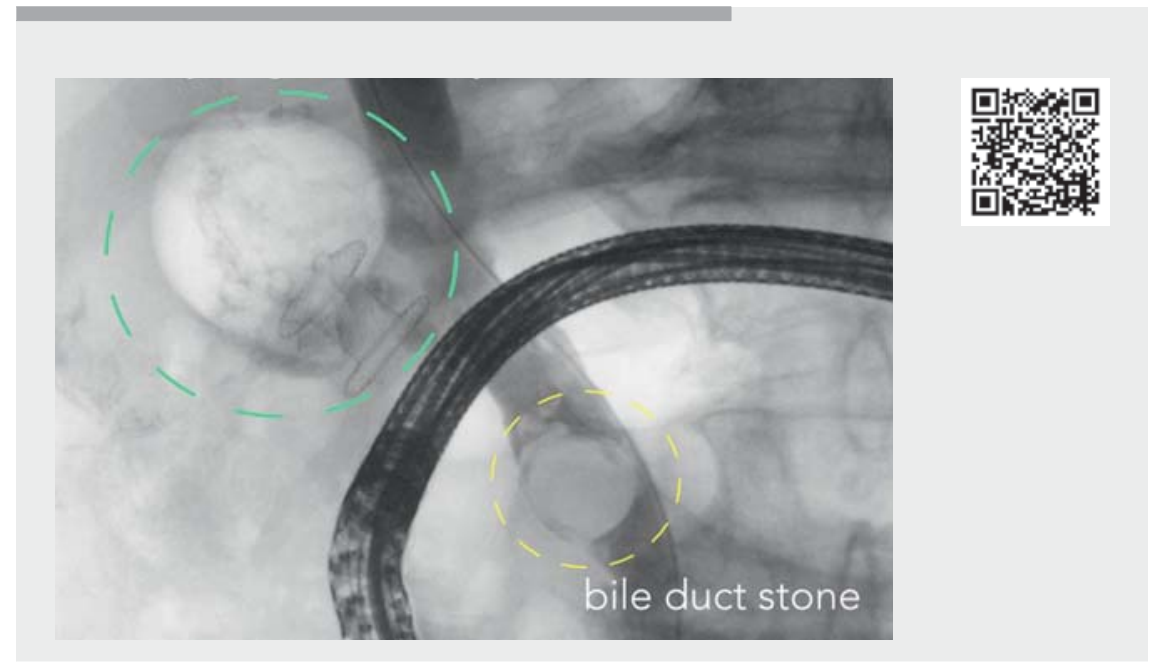

$\checkmark$ Video 1 Endoscopic ultrasound-guided cholecystogastrostomy followed by cholangioscopy with Spyglass through the lumen of the lumen-apposing metal stent and lithotripsy of gallbladder stones.

of purulent bile and sludge and was followed by mechanical lithotripsy, without success. Lastly, a biliary stent was implanted in the CBD.

Owing to the gallbladder's empyema and severe comorbidities that dramatically increased operative risk, the patient qualified for gallbladder decompression through a cholecystogastrostomy under EUS guidance using a Hot Axios stent $(10 \times 10 \mathrm{~mm})$ (Boston Scientific, Marlborough, Massachusetts, USA) (ฉ Fig.1). No intra- or postprocedural complications were observed, allowing safe discharge home 3 days later.

A second ERCP for common bile duct stone clearance with a successful cholangioscopy (SpyGlass, SpyScope, Boston Scientific) and electrohydraulic lithotripsy (EHL) (Autolith Touch Biliary EHL System, Boston Scientific) of the largest CBD stone was performed.

The patient's general state of health disqualified him from surgery. Thus, a chole- 
cystoscopy through the lumen of the previously implanted lumen-apposing metal stent (LAMS) using the SpyScope cholangioscope was done (via the working channel of the colonoscope) ( $\mathbf{F i g . 2}$ ). Numerous gallstones were found, some of them larger than the LAMS lumen. Therefore, EHL of stones was performed, enabling the removal of smaller fragments from the gallbladder into the stomach using a mesh. Cholecystoscopy after stone removal showed a healthy gallbladder wall and no obstruction at the cystic duct ( $>$ Fig. 3 , > Fig. 4 ). The patient was discharged home on the first day after the procedure. Presently the patient remains in good health with no symptoms.

This case is interesting for three main reasons. First, we demonstrate that the emphysematous gallbladder's endoscopic drainage is safe in a high-risk surgical candidate. Second, we show that intra-gallbladder EHL is feasible entering through the previous LAMS. Third, we used the Spyglass system through the colonoscope, which allows for a forward view, in contrast to using it through a duodenoscope. In sum, EUS-guided cholecytogastrostomy followed by Spyglass cholecystoscopy and lithotripsy allows radical treatment of gallbladder empyema and cholelithiasis simultaneously with ERCP treatment of choledocholithiasis ( Video 1).

Endoscopy_UCTN_Code_TTT_1AR_2AH

\section{Competing interests}

The authors declare that they have no conflict of interest.

The authors

Artur Raiter ${ }^{1}$, Joanna Szełemej ${ }^{1}$, Katarzyna Kozłowska-Petriczko², Jan Petriczko ${ }^{3}$, Katarzyna M. Pawlak ${ }^{4} \odot$

1 Department of Endoscopy, Specialist Hospital of Alfred Sokolowski, Wałbrzych, Poland

2 Department of Gastroenterology and Internal Medicine, SPWSZ Hospital, Szczecin, Poland

3 Department of Plastic, Endocrine and General Surgery, Pomeranian Medical University, Szczecin, Poland

4 Department of Gastroenterology, Hospital of the Ministry of Internal Affairs in Szczecin, Poland

Corresponding author

Katarzyna M. Pawlak, MD, PhD Hospital of the Ministry of Internal Affairs, Jagiellońska 44, 70-382 Szczecin, Poland pawlakatarzyna@gmail.com

\section{References}

[1] Oh D, Song T], Cho DH et al. EUS-guided cholecystostomy versus endoscopic transpapillary cholecystostomy for acute cholecystitis in high-risk surgical patients. Gastrointest Endosc 2019; 89: 289-298
[2] James TW, Baron TH. EUS-guided gallbladder drainage: a review of current practices and procedures. Endosc Ultrasound 2019; 8: S28-S34

[3] Chaudhary S, Sun S. Endoscopic ultrasoundguided gallbladder drainage: redefines the boundaries. Endosc Ultrasound 2016; 5: 281-283

Bibliography

Endoscopy 2022; 54: E55-E56

DOI 10.1055/a-1352-2468

ISSN 0013-726X

published online 5.3.2021

(c) 2021. Thieme. All rights reserved.

Georg Thieme Verlag KG, Rüdigerstraße 14, 70469 Stuttgart, Germany

\section{ENDOSCOPY E-VIDEOS}

https://eref.thieme.de/e-videos

口回 Endoscopy E-Videos is an open access online section, 靣: reporting on interesting cases and new techniques in gastroenterological endoscopy. All papers include a high quality video and all contributions are freely accessible online. Processing charges apply (currently EUR 375), discounts and wavers acc. to HINARI are available.

This section has its own submission website at

https://mc.manuscriptcentral.com/e-videos 